\title{
Preface: CCWI 2013
}

\author{
B. Brunone ${ }^{1}$, M. Ferrante ${ }^{1}$, S. Meniconi ${ }^{1}$, and L. Berardi ${ }^{2}$ \\ ${ }^{1}$ Dipartimento di Ingegneria Civile ed Ambientale (DICA), The University of Perugia, via G. Duranti 93, \\ 06125 Perugia, Italy \\ ${ }^{2}$ Dipartimento di Ingegneria Civile e Architettura, The Technical University of Bari, via Orabona 4, \\ 70125 Bari, Italy
}

Correspondence to: B. Brunone (bruno.brunone@unipg.it)

Since 1991 "Computing and Control for the Water Industry - CCWI" is a well-established series of bi-annual meetings.

On 2-4 September 2013, the 12th edition (CCWI2013) was held in Perugia (Italy) and was focused on Information for Water Systems and Smart Cities. CCWI2013 emphasized the integration between the more conventional themes of the analysis and planning of water systems and information technology. Such an integration offers opportunities for design solutions and innovative models for the challenging problems of water system management in an urban perspective, a key concept for smart cities (Brunone and Giustolisi, 2014). The large number of presentations - more than 200 with many young researchers from Europe and overseas confirmed the interest for CCWI2013 themes and the increasing success of CCWI Conferences (Fig. 1).

This CCWI2013 special issue contains a selection of extended CCWI2013 papers which give a taste of the Proceedings of the Conference published on Procedia Engineering Elsevier (www.sciencedirect.com/science/journal/ 18777058/70). In fact their topics range from sustainabilitybased indicators of the urban water systems (Behzadian et al., 2014), design and control parameters in water treatment (Ramphal and Sibiya, 2014), numerical simulation of the transition between surface and pressurized flow (Fernández-Pato and García-Navarro, 2014) to optimisation of pump and valve schedules in complex large-scale water distribution networks (Skworcow et al., 2014), and a real data-based model to simulate the behavior of a pumping station equipped with variable speed pumps (Capponi et al., 2014).

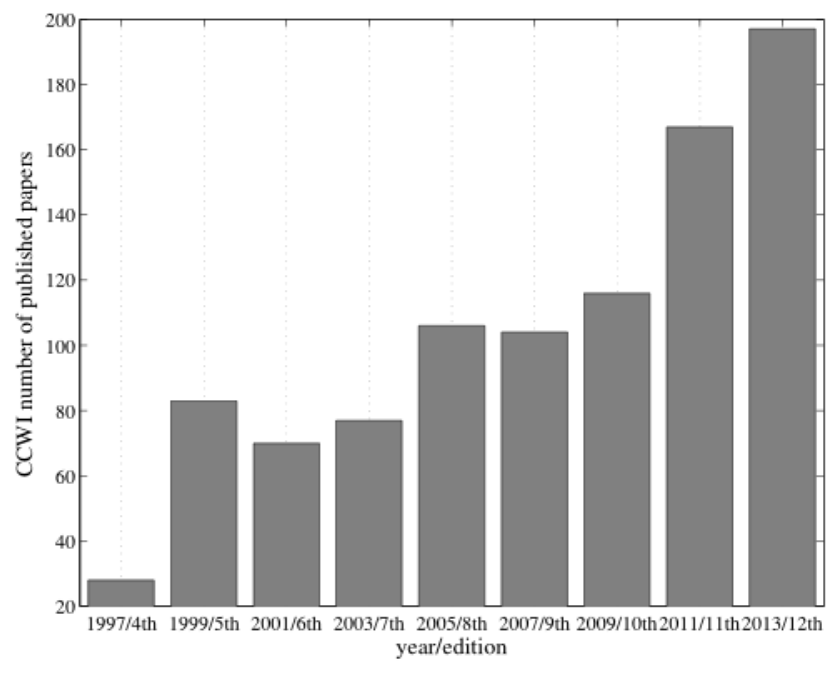

Figure 1. Last nine editions of CCWI conferences: number of papers published in the proceedings (from Brunone and Giustolisi, 2014).

Next editions of CCWI Conferences have been already planned by the Water Distribution Systems Analysis (WDSA) Standing Committee within EWRI (Environmental and Water Research Institute): CCWI2015 in Leicester (UK), CCWI2016 in Amsterdam (NL), CCWI2017 in Sheffield (UK), and 20th WDSA and CCWI2018 as a joint conference. The WDSA Standing Committee - probably the most organized non-formal group (!) - is chaired by Dominic Boccelli (University of Cincinnati), with Morris Maslia (Agency for Toxic Substances and Disease Registry, Atlanta, Georgia) as Vice Chair, J. E. (Kobus) van Zyl (University of Cape Town, South Africa) as Secretary, and Avi Ostfeld (Technion, Haifa, Israel), as Past Chair. 


\section{References}

Behzadian, K., Kapelan, Z., Venkatesh, G., Brattebø, H., and Sægrov, S.: WaterMet2: a tool for integrated analysis of sustainability-based performance of urban water systems, Drink. Water Eng. Sci., 7, 63-72, doi:10.5194/dwes-7-63-2014, 2014.

Brunone, B. and Giustolisi, O.: Preface, in: 12th International Conference on Computing and Control for the Water Industry, CCWI2013, Procedia Engineering, Elsevier, 70, 1-3, doi:10.1016/j.proeng.2014.02.001, 2014.

Capponi, C., Ferrante, M., Pedroni, M., Brunone, B., Meniconi, S., Zaghini, M., and Leoni, F.: Functioning conditions of the Casale pumping station in Mantova, Italy, Drink. Water Eng. Sci. Discuss., 7, 151-168, doi:10.5194/dwesd-7-151-2014, 2014.
Fernández-Pato, J. and García-Navarro, P.: Finite volume simulation of unsteady water pipe flow, Drink. Water Eng. Sci., 7, 8392, doi:10.5194/dwes-7-83-2014, 2014.

Ramphal, S. R. and Sibiya, M. S.: Optimization of coagulationflocculation parameters using a photometric dispersion analyser, Drink. Water Eng. Sci., 7, 73-82, doi:10.5194/dwes-7-73-2014, 2014.

Skworcow, P., Paluszczyszyn, D., and Ulanicki, B.: Pump schedules optimisation with pressure aspects in complex large-scale water distribution systems, Drink. Water Eng. Sci., 7, 53-62, doi:10.5194/dwes-7-53-2014, 2014. 